\title{
Health Education for the Elderly
}

\author{
Ayla Kececi and Serap Bulduk \\ Duzce University/Vocational School of Health Services, \\ Turkey
}

\section{Introduction}

Health promotion and wellness are a great responsibility, particularly for all health care providers who work with elderly people. Some health care providers claim that because of their age, activities pertaining to prophylactic measures, health and wellness maintenance will not be helpful to elderly people. On the contrary, wellbeing should not be regarded as a concept specifically relevant to younger individuals. The wellness concept is applicable to every age from older adults to the young (Reicherter \& Greene, 2005; Tabloski, 2010).

The world population on the whole is growing older and wellness and common diseases (infectious diseases, acute illnesses, chronic diseases and degenerative diseases, etc.) have been changing. Although many chronic diseases cause serious defects, some studies show that if a healthy life style is adopted and maintained, these defects can be delayed. Besides, these illnesses generally pose risk factors for individuals and their life styles. Studies on wellness and the prevention of diseases have been found effective, especially in providing lifelong behavioral change. Since the elderly population is at a huge risk of major diseases and defects, members of health care units should handle their education carefully. Through such education, benefits are provided regarding protective and wellness development for many elderly people (Reicherter \& Greene, 2005; Tabloski, 2010).

Health education is a concept directly linked to health promotion in both clinical and educational preparation fields. Health promotion reform has developed an increasing interest in acute injuries and diseases from the mid-1980s. However, opportunities to promote health have generally been neglected (Choi et al., 2010).

Health education increases individuals' knowledge of health and health care and makes them informed about their health care choices. Prophylactic health behaviors (such as physical activities and having healthy food) keep older adults' lives active, delay going to nursing homes and increase satisfaction with life. Among the topics where elderly people need help most, a lack of knowledge comes first (Leung et al., 2006). World Health Organization (WHO) has emphasized the importance of health education to support health care needs and health promotion for elderly people (Rana et al., 2010).

Health education requires a careful handling of knowledge, attitude, objective, perception, social status, power structure, cultural practices and other social perspectives. Health education is not a concept about individuals or their families but can profoundly affect individuals' social status (Glanz et al., 2008). 
An ageing population makes countries face many kinds of struggle in terms of health care and education. First of all, social support and care offered by elderly people's friends and family members can be inadequate (Hoving et al., 2010). If elderly people can afford health-protective and self-management behaviors in their daily lives, they can live more independently. However, a higher prevalence of chronic diseases like diabetes, cancer, heart diseases and dementia in this age group makes self-management of these illnesses and patient education more complicated. Educational programs for elderly people have complicated treatment plans because their age will increase their awareness level of medical treatment (Shen et al., 2006). Likewise, in studies conducted in different parts of the world, it was found that there is a need for serious educational programs related to old age (Liu\&Wong, 1997; Kahn et.al., 2004; Doucette\&Andersen, 2005; Koh, 2011; Vintila et.al., 2011).

Health care personnel's personal belief that elderly people have a poor understanding and learning ability has been an important obstacle in providing elderly people with an effective education. The myths about ageing have regarded elder people as unproductive, resistant to change, impotent and stereotyped individuals. In addition, health care personnel's lack of knowledge and skill may often prevent them from seeing all behavioral symptoms. For instance, behaviors of an elderly person who suffers from a mental disorder due to dementia can be seen as manipulative, or an older person with impaired hearing may respond intricately or inappropriately. In these situations, elderly people are considered "difficult" or "complicated" by health service providers (Smith, 2006). Many elderly people, however, do not experience biological, psychological and socially excessive negative effects. Instead, for those who are physically fit and extrovert, social and psychological abilities continue. On the other hand, experiencing some changes may disrupt learning in the health education process. Below are the commonly seen changes that may affect the learning process in elderly people (Tabloski, 2010; Cornett, 2011).

- Physical changes: The beginning, direction and order of the ageing process of elderly people depend physically and biologically on genetic and environmental factors. Degenerative changes may occur in hearing, seeing, feeling and responding skills. Spatial variability, mobility, and motor coordination may be spoilt. The working level may affect most body systems (Tabloski, 2010; Cornett, 2011 ).

- Psychological changes: The psychological aspect of ageing is related to a person's adaptation capacity. There might be changes in perception and memory, learning and problem solving, psychological state and attitude, sense of self and personality. Problems with memory in particular are common. The most declining cognitive skills are reported to be thinking with numbers and retention skills. The least decrease is seen in interpreting ideas and events, establishing relationships between events and ideas, generalizing, vocabulary and knowledge. Besides, regardless of a recession in their ability to learn, memory and intelligence, the rich life experience of elderly people makes their ideas valuable and health education should benefit from this experience. Another factor that can psychologically affect elderly people is losses. The loss of a former role and status, wife, friend, economical power and familiarity can be experienced. Due to these changes, self-respect diminishes and fulfillment decreases. Evaluating elderly people in terms of the losses they experience and the effects of these losses on their struggle is extremely important. Also, loss of confidence suppresses the ability or readiness to learn. However, preparing the person by strengthening self- 
esteem with personal achievements and skills is an important strategy. Safety and safety needs are major anxiety factors for the elderly in a crisis situation. Unless these needs are satisfied, an active elderly person cannot actively participate in health education (Cornett, 2011).

- Socio-Cultural Changes: Social change and cultural factors affect self-care of the elderly as a personal component. Independency is a crucial purpose for most elderly people regardless of their health conditions. This is an expression of self-respect and pride. Elderly people seek help in gaining independency. The health education offered should contribute to their self-management skills. As their physical power decreases, elderly people move away from the activities that require mobility and much energy and prefer to choose more passive life styles. Especially the ones with poor education pass their time with limited activities. Yet, mentally and socially active elderly people face the limitations derived from ageing at a low level (Tabloski, 2010). An older adult's ability to cope with problems is closely related to health care and education. If an elderly person sees himself or herself as an experienced and wise individual, education can be built on these positive experiences and ways of adapting to the occurring inevitable changes can be sought. However, unrealistic goals and demands should be explained to the less adaptive people before the education (Cornett, 2011). In some countries, the fact that elderly people do not want to stay in their own houses or places specifically for elderly people is an obstacle in providing and maintaining health care. Additionally, physical, social and environmental liabilities cause problems regarding benefiting from services to maintain wellness. For this reason, all the liabilities that might affect elderly people's learning process should be determined and minimized prior to education (Reicherter \& Greene, 2005).

\section{Older adult learners}

Knowing the learner is the key to successful teaching! Some features of adult and older adult learners constitute the key.

Self-concept: The self-concept of an adult learner is to be able to direct himself or herself and to be mature and positive in society. Adults want to make their own decisions and take the responsibility for the consequences of these decisions. They expect to be respected and regarded as unique beings (DeYoung, 2009; Cornett, 2011). Ericson mentioned some features of adulthood in the eighth phase of the human development period which he defines as "self-integrity." According to Ericson, in this phase, maturity and unity of the personality features gained in the previous phase are the most crucial task. Self-integrity is ego's having an order and meaning in itself. In other words, it is the acceptance of a life with all its positive and negative aspects. This prevents welcoming the future with fear and anxiety. However, the most important sign of lacking self-integrity is the idea that past days were not spent well, despair and fear of death. Especially in the process of health education for the elderly, educators must show respect for elderly people's needs, choices and their desire to manage their own lives. Creating an environment which makes them feel accepted, respected and trusted will encourage them to express their feelings and thoughts away from fear and pressure. For this reason, educators should ask elderly people how they would like to be called and call them that way. Adults are motivated to learn when they realize that they need to learn. Learners must be helped to express their feelings about their needs 
because they want to take the responsibility for their learning and management of their lives in the learning process. For this purpose, educators regard every interaction with elderly people as an opportunity to support their self-concept (Karaoz \& Aksayan, 2009, Cornett, 2011).

Life Experiences: An older adult has considerable background information and life experiences in her/his lifetime. Life experiences are rich sources for learning. When an adult's experiences are supported and approved by others, positive feelings come into being since these experiences constitute her or his self-identity. If these experiences are not noticed, the person might feel rejected (Tabloski , 2010). Negative past experiences should be identified and dealt with since they might disrupt the learning process. For instance, an elderly person who has had bad experiences with "ageing and chronic diseases" might think that the education offered will not have any positive effect on him or her and because of this he or she may not learn. Positive experiences of adults should be used as an experimental teaching strategy. If new learning is related to a person's past experiences, they become more appropriate and meaningful. New self-management skills become more meaningful when a person adapts himself or herself to routine and a normal life style. Sharing their experiences with people having similar problems contribute to the problemsolving process among older adults (DeYoung, 2009; Cornett, 2011).

Being ready to learn: Before an effective education, adult learners should be ready for learning. When an individual is ready to learn, he or she will make the most of it (Gokkoca, 2001). People's attitudes and responses to a situation that threatens their wellness are mostly determined by an illness causing loss of control and self-confidence, disability and perceptions and experiences related to other factors. Readiness is strongly affected by individuals' social roles and developmental tasks. Some social roles and developmental roles after adulthood can be listed as an adaptation to decreasing physical strength and health, retirement and a decrease in income, and the death of a spouse and other family members (DeYoung, 2009; Cornett, 2011).

Readiness to learn and problem-solving skills can be enhanced by role-plays and group work with adults who have the same roles (Cornett, 2011). Previous achievements of elderly people have been an important motivating factor in the things that should be done and will be done in the future. Prompts like "......you can do it, you can achieve it" strengthen their belief in self-efficacy. Individuals' physical or mental conditions strengthen or weaken their belief in performing an expected task (Bikmaz, 2006).

Problem-oriented or Goal-oriented: Adult learners are motivated when there is a problem or crisis concerning them. In other words, they have a different point of view when compared to the young (Cornett, 2011, Gokkoca, 2001). They see learning as a way to overcome these problems and learn the things that are related to them and helpful to the fulfillment of responsibilities. Adult education is behaviorist oriented (how is it done?). However, in order to limit the education circumstances, minimum requirements such as "vital" or "good to know" must be known. Patients should be provided with practical solutions to their problems and should be immediately assisted with hands-on-practice and problem-solving sessions to practice new information. Unless patients require information on this issue and understand self-care, providing information on the illness process is not a priority. On the other hand, urgent needs should be prioritized. If potential problems patients might face are 
not known, questions about their concerns and aiming to know how to handle the situation should be asked. This gives an idea of the "rehearsal" situation or the possible response in case a problem occurs (DeYoung, 2009; Cornett, 2011).

From another point of view, elderly people's values and beliefs can be a facilitator or obstacle in caring for their health. For instance, elderly adult symptoms (e.g., tiredness, depression) are not taken seriously, requiring medical aid, and are regarded as an inevitable part of old age. Advanced age can affect the efforts of protecting health and selfmanagement in a psychosocial context. For instance, due to changes in social relations (e.g., being divorced or losing a spouse), the amount and quality of social support might have changed. Following a balanced diet and positive sickness should be taken into consideration (Connell, 1999, Cornett, 2011). Since the results are related to support, elderly adults have more problems with their health and self-management (e.g., diet, exercise) compared to young and middle-aged adults. These examples are only a few of how health education will be affected in the context of physical and psychosocial changes. Age-related changes should always be taken into consideration, especially in the design, implementation and evaluation of health education programs.

\section{Possible barriers to education of the elderly}

Possible barriers that need to be considered during teaching should be known so that the learning potential of the elderly can be realized. These barriers can be mostly classified as sensory loses, mental illnesses and chronic diseases (Tabloski, 2010; Cornett 2011).

\subsection{Sensory losses}

The five senses tend to decline with advancing age. Sensory losses are problems with one or more senses (auditory, visual, tactile, olfactory, or taste). Hearing and vision changes affect communication while the other losses can affect thinking processes in the elderly (Tabloski, 2010; Smith, 2006).

\subsubsection{Hearing deficiency}

Individuals with hearing problems are people who either completely lost this sense or have decreased sensitivity to sounds. Individuals experience various obstacles related to communication in the process of patient education depending on their level of hearing loss. Individuals with hearing loss may be unable to speak or may have a limited verbal ability and a weak vocabulary. Just like other healthy people, these individuals will need health care or health education throughout their lives. Although the health educator offers support in different ways, individuals with hearing loss always have to use their other senses to get information (Bastable, 2008; Cornett, 2011). A general hearing loss may be the result of an illness, noise or bone changes while gradual hearing loss can bring about the loss of sounds like S, SH and $\mathrm{CH}$ or high frequency sounds (Smith, 2006). There are so many different ways of communication with individuals with hearing loss. First of all, educators should discover the individual's preference to communicate. Sign language, written information, lip reading and visual support are the most commonly used alternatives. In addition to these means, facial expressions, gestures and mimics should be included in the communication process for sharing information. During all education sessions, educators should be natural and not 
strict, speak clearly with simple sentences, adopt a way of asking for consent like a touch of the hand before starting to talk, set up face-to-face communication and maintain a distance of about $100 \mathrm{~cm}$ ( 6 feet). In conclusion, there is not just one way to communicate with individuals suffering from hearing deficiency. What matters is determining whether the messages are received correctly and if they are clear (Bastable, 2008; Tabloski, 2010; Cornett, 2011).

\subsubsection{Visual deficiencies}

Vision deficiencies are particularly common among older people. Most vision problems like glaucoma, cataracts and macular degeneration occur in the retina. Changes in vision can usually be seen in the form of a reduced ability to see distant objects, a loss of the ability to see objects on the side, and a loss of the ability to see very close (even faces) and some colors (peripheral vision) (Smith, 2006). Older people with reduced visual acuity may display behaviors such as dimming eyes, needing to touch, reluctance to communicate or withdrawal (Bastable, 2008; Cornett, 2011). The following are some recommendations for education of the elderly with a reduced visual ability:

- Education materials should be prepared in a format and size elderly people can easily see,

- Their other senses (touch, smell, hearing, taste) should be improved,

- It should be considered that especially hearing and touch are significant for sharing information,

- The procedures should be explained as descriptively as possible,

- Elderly individuals should be allowed to touch, hold and smell the related materials,

- Materials should be prepared in larger fonts for the elderly with visual deficiencies,

- Education materials should be prepared in black on a white background or in white on a black background,

- Contrasting colors should be preferred when using different colors,

Audio recording devices should also be included in the educational process, and Computers and texts using the Braille alphabet should be preferred if possible (Bastable, 2008).

\subsubsection{Deficiencies of smell and taste}

Formation of papillary atrophy in the tongue with ageing brings about losses in sensing sweet and salty tastes. Some chronic diseases (e.g., Alzheimer's disease, Parkinson's disease) can affect the sense of smell and taste. Similarly, drugs, surgical interventions and environmental factors contribute to losses in taste and smell senses. Elderly people need the same nutrients as young people but in different amounts. As a result of ageing due to factors that negatively affect nutrition, a lack of nutrients in the elderly is found more often.

Elderly people need the same nutrients as young people but in different amounts. Due to the factors that negatively affect nutrition as a result of ageing, a lack of nutrients is more prevalent in the elderly. For this reason, one should be more careful about consuming some nutrients in terms of energy, protein, folate, vitamin B12, calcium, vitamin D, iron, zinc, and riboflavin. All these elements, which are necessary for elderly individuals, act as catalysts for certain diseases that may affect their learning process. For this reason, the health educator should evaluate the levels of these substances, especially when assessing an individual's physical characteristics (Tabloski, 2010). 


\subsubsection{Deficiencies of sense of touch}

Older adults may suffer from a reduction in feeling cold or hot and have pain due to the decrease in the thickness of the dermis of the skin in old age, vitamin D synthesis, its protection against micro-organisms, capillaries, collagen production, and senses of touch and pressure (Tabloski, 2010).

\subsection{Mental illnesses}

Individuals with mental disorders have possibly been existing in community mental health centers, in society, in the family or workplace environments for the last 25 years. People who work with such individuals should consider their feelings and thoughts about mental illnesses before the start of the teaching-learning process. Although there are some basic principles in the education of individuals with mental illnesses, there are still some specific instructional strategies that need to be considered. One of the first steps in any educational attempt is mental diagnostics. Firstly, in order to diagnose the anxiety level of an individual, it is necessary to determine whether the individual has any mental incapability or insufficiency. When there is an emotional threat depending on the mental illness, the individual's anxiety level will increase and the level of readiness will decrease. While working with an aged individual with a mental illness, the following points must be considered:

- $\quad$ Training must be organized according to their needs.

- Learning desire and the joy of life should be kept alive.

- Teaching should be performed by using short and simple words and information must be repeated as often as possible. Important pieces of information should be written on cards, certain techniques such as drawing one of the cards which is appropriate for them should be used and plain symbols and drawings must be used.

- Sessions should be kept short and frequently repeated. (Four fifteen-minute sessions instead of a one-hour session, etc.)

- All possible sources for the individual and his or her family should be used, all appropriate learning styles for the individual must be sought and training must be organized in this direction, and training should be supported by visual tools such as computers and videos.

- Assistance from the individual's family members, relatives, neighbors and volunteers must be accepted.

- Instead of an authoritarian attitude, a calm and understanding approach must be adopted in communication (Smith, 2006; Bastable, 2008; Kurt, 2000).

In addition, since individuals with mental illness face stigma both in society and in the family, it is crucial to determine appropriate instructional strategies. Motivation of individuals with mental illness is quite an important issue. After completing the program, giving a certificate to participants will increase the motivation of each individual. However, it is necessary to give useful information to increase the quality of life of elderly individuals with mental illnesses. As for healthy individuals, achieving and maintaining the independence and self-government of such individuals are extremely important (Smith, 2006; Bastable, 2008; Cornett, 2011). 


\subsection{Chronic diseases}

The learning process of individuals with chronic diseases is full of difficulties. Many diseases have many phases that may affect the educational needs of the individual patients and their families. Therefore, there is no unique approach to provide the most appropriate teaching-learning. What matters is the start of the disease, its progress and intensity. The perception and the reaction of these individuals' families to the learning-teaching process are also very important. Families are in need of education and information on the limitations related to the changes and limitations in the lives of individuals. Usually, these individuals experience conflicts between their needs to become dependent or independent in their lives. Maintaining energy and independence could sometimes be physically and emotionally repressing. Living with a chronic disease often causes a loss of role and some other changes. When a loss of role and a decrease in self-respect appear, the situation affects readiness for learning. Thus, it will be right to take the following actions:

- Prevent medical crises and problems before they happen.

- Take control of symptoms.

- Apply the existing treatment plan and provide the management of self-care-related problems.

- Prevent their social isolation from other people.

- Help them balance their living standards and their relations with other people.

- To provide changes related to illness, adjust yourself.

- Provide funding for treatment if necessary.

- Prevent psychological, marital and family problems from happening (Tabloski, 2010; Cornett, 2011).

\section{Health education process for the elderly}

People offering health education have many responsibilities to determine the needs of the elderly and to take actions according to their needs (Kulakçı \& Emiroğlu, 2011). The main objective of health education is to provide individuals and society with assistance so that they can lead a healthy life through their own efforts and actions. Therefore, health education supports and develops all kinds of individual learning processes. Similarly, it makes changes in the beliefs and value systems of individuals, their attitudes and skill levels; in other words, it changes their lifestyles (Tabak, 2000).

The role of health educators is to apply education to develop responsibilities for the self-care of individuals who are incompetent, which is also what they are supposed to do. Families increasingly become more involved in the work of self-care-incompetent individuals' rehabilitation, and individuals with poor self-care are expecting to become a part of life in the community. In addition, health educators have responsibilities to determine the learning needs of patients in cooperation with families, to plan appropriate educational initiatives and to provide a supportive environment (Bastable, 2008).

At the beginning of this education, the problems of patients, short and long-term consequences of their deficiencies, the effectiveness of coping mechanisms, and their needs related to the sensorimotor, cognitive, perceptual and communicational inadequacies need to be defined. Patients' level of knowledge related to their inadequacies, the amount and the 
kinds of information that may affect the needed behaviors and the readiness level for providing learning should also be determined separately. In order to determine the readiness levels of the patients, the following questions should be asked (Bastable, 2008):

- Are other individuals and family members interested in patients' learning, do they ask questions about problem solving, or do they take patients' needs into consideration?

- Is there insufficient information, vision or hearing problems that prevent learning?

- If there are any sensory or motor changes, will the people around the patients be participative and supportive towards instructional activities? What is the most appropriate learning style that is applicable to the patient's self-care activities?

- Is there compatibility between the patient's and family's goals?

- Does the patient have learning values and skills for the purpose of functional development?

After determining the level of readiness of the elderly, educational activities should be structured in accordance with the models of health education. These models are described below.

\subsection{Health behavior models}

Health behavior models and theories are inherently associated with health behavior measurements because they explain what they are to assess. The models used most in elderly individuals in articles published in the 2000s in education, health and behavioral sciences in the field of a theoretical framework are the Health Belief Model, the Theory of Reasoned Action/Planned Behavior, the Social Cognitive Theory and the Transtheoretical Model. These four health behavior models, which can be utilized in planning the health education process for the elderly, are summarized below.

\subsubsection{Health belief model}

The Health Belief Model (HBM) is the oldest of all the theories examined here. The Health Belief Model holds that people are more likely to take action to prevent disease when they realize that

- they can catch the disease themselves,

- the disease can have serious consequences,

- $\quad$ preventive behavior effectively will prevent disease, and

- benefits of reducing the dangers of the situation clearly outweigh the damages of taking action.

Affected by mediating variables, these four factors have an influence on the expectations of the known dangers and consequences of the disease. Therefore, they indirectly affect the possibility of exhibiting preventive health behavior.

Health Belief Model health screening is used to intervene in the disease, disease role and protective behaviors. This model has been subject to a number of changes since its development. Table 1 shows the four constructs model, the most common description of the Health Belief Model. The four main constructs of the model are perceived susceptibility, perceived severity, perceived benefits (efficacy), and perceived barriers (harms) (Champion \& Skinner, 2008). 
Constructs

Perceived susceptibility

Perceived severity

Perceived benefits

Perceived barriers

Clues to action

Self-efficacy

\section{Explanations}

An individual's assessment of his or her risk of getting the condition

An individual's assessment of the seriousness of the condition, treatment of the condition and its potential consequences

An individual's assessment of the positive consequences of adopting the promoted behavior

An individual's assessment of the influences that facilitate or discourage adoption of the promoted behavior or its psychological and physical consequences

Experiences and strategies promoting the desired behavior

An individual's self-assessment of ability to successfully adopt

the desired behavior

From Redding, C.A., Rossi, J.S., Rossi, S.R., Velicer, W.F., \& Prochaska, J.O. (2000). Health Behaviour Model. The International Electronic Journal of Health Education, Vol. 3 (Special Issue), pp. 180-193. http://www.iejhe.siu.edu

Table 1. Health Belief Model Constructs

\subsubsection{Theory of reasoned action/planned behavior}

The Theory of Reasoned Action (TRA) is a socio-psychological approach aimed at understanding and predicting the determinants of health behavior and is a widely-used theory of prediction. The Theory of Reasoned Action has been applied to many healthrelated behaviors in the elderly including weight loss, smoking, excessive alcohol consumption, HIV risk behaviors and mammography screening, etc. According to the Theory of Reasoned Action, the intention of adopting a behavior is closely associated with realization of that behavior. The Theory of Reasoned Action is based on two main assumptions: behavior is controlled by will and people are rational. The Theory of Reasoned Action holds that individuals believe: We do something because we have chosen to do so and go through a logical decision-making process when we choose and plan our behavior.

Designed to predict behavior by looking at the intention, the Theory of Reasoned Action claims mathematical relationships between beliefs, attitudes, intensions and behavior. A modified version of the Theory of Reasoned Action adds perceived behavioral control to the theory. It is called the Theory of Planned Behavior (TPB) (Montano \& Kasprzyk, 2008). Table 2 describes the main concepts of the Theory of Reasoned Action and the Theory of Planned Behavior. 


\begin{tabular}{|c|c|}
\hline Concepts & Explanations \\
\hline Behavioral intention & Possibility of undertaking the perceived behavior \\
\hline Attitudes & $\begin{array}{l}\text { The sum of beliefs about a particular behavior, } \\
\text { weighted by evaluations of these beliefs }\end{array}$ \\
\hline Behavioral belief & $\begin{array}{l}\text { An individual's belief about consequences of } \\
\text { a particular behavior }\end{array}$ \\
\hline \multicolumn{2}{|l|}{ Evaluation of behavioural belief } \\
\hline & $\begin{array}{l}\text { An individual's positive or negative evaluation of } \\
\text { self-performance of the particular behavior }\end{array}$ \\
\hline Subjective norm & $\begin{array}{l}\text { The sum of normative beliefs and motivation to } \\
\text { comply with }\end{array}$ \\
\hline Normative belief & $\begin{array}{l}\text { An individual's perception of the particular } \\
\text { behavior, which is influenced by the judgment of } \\
\text { others }\end{array}$ \\
\hline Motivation to comply & $\begin{array}{l}\text { Every personal contact, an individual's drive to } \\
\text { engage }\end{array}$ \\
\hline Perceived behavioral control & The sum of control beliefs and perceived power \\
\hline Control beliefs & $\begin{array}{l}\text { Possibility of the presence of factors that may } \\
\text { facilitate or impede performance of the behavior }\end{array}$ \\
\hline Perceived power & $\begin{array}{l}\text { The effect of each situation that may facilitate or } \\
\text { impede performance of the behavior }\end{array}$ \\
\hline
\end{tabular}

From Redding, C.A., Rossi, J.S., Rossi, S.R., Velicer, W.F., \& Prochaska, J.O. (2000). Health Behaviour Model. The International Electronic Journal of Health Education, Vol. 3 (Special Issue), pp. 180-193. http://www.iejhe.siu.edu

Table 2. Theory of Reasoned Action/Planned Behavior

The ultimate goal of the Reasoned Action Theory is to predict. The theory holds that the intentions of the behavior affect the behavior. The three main variables that affect the intention are subjective norms, attitudes and self-efficacy. Subjective norms involve an individual's assessment of what significant others think of his or her ability to undertake a behavior. For example, an elderly person with a cardiac condition tries to prevent complications from the condition by taking his or her medication on a regular basis and has regular medical checks. The intention of this individual is partly determined by the idea of his or her spouse or a friend who could be a role model: "What would he or she do if he or she were me?" Attitudes can be conceptualized in terms of values. In other words, a set of values can be developed in relation to behaviors. For instance, "healthy eating is a good way to prevent heart disease and/or cancer" (Redding et al. 2000; Montano \& Kasprzyk, 2008).

\subsubsection{Social cognitive theory}

This theory goes far beyond individual factors to explain health behavior change and also utilizes environmental and social factors. Indeed, this theory is the most comprehensive model of human behavior proposed so far. Bandura's Social Cognitive Theory (SCT) is a behavioral theory of prediction that has a neutral approach to health behavior change. This 
theory is widely applied in health care in terms of health behaviors in prevention, health promotion, and improving the living conditions of unhealthy behavior. The Social Cognitive Theory emphasizes what people think and its impact on behavior. Based on triadic reciprocality of behavior, the Social Cognitive Theory suggests that behavior can be described using three key concepts, each of which serves as a determinant of one another. The basic regulatory principle of the Social Cognitive Theory is reciprocal determinism. This important concept represents a continuous and dynamic interaction between the individual, the environment and behavior. Hence, a change in any of these factors will affect the other two. The Social Cognitive Theory includes several auxiliary concepts for each of the three main concepts in order to explain the theory. Table 3 explains all the key concepts of the Social Cognitive Theory (Redding et al., 2000).

\begin{tabular}{|c|c|}
\hline Concepts & Explanations \\
\hline Environmental & Environmental factors other than the person \\
\hline Situation & Individual's perception of the environment \\
\hline Behavioral Capability & $\begin{array}{l}\text { The knowledge and skills of an individual in } \\
\text { performing a behavior }\end{array}$ \\
\hline Expectations & $\begin{array}{l}\text { The prospects of an individual performing a } \\
\text { behavior }\end{array}$ \\
\hline Expectancies & $\begin{array}{l}\text { An individual's assessment of how the results } \\
\text { could be good or bad }\end{array}$ \\
\hline Self-control & Regulation of one's own behavior \\
\hline Observational Learning & $\begin{array}{l}\text { Observing behaviors of other people to acquire } \\
\text { new behaviors }\end{array}$ \\
\hline Reinforcements & $\begin{array}{l}\text { Reaction to the individual's behavior that } \\
\text { affects the possibility of repetition }\end{array}$ \\
\hline Self-efficacy & $\begin{array}{l}\text { An individual's self-belief in achievement in } \\
\text { performing a behavior. Emotional coping }\end{array}$ \\
\hline Emotional Coping Responses & $\begin{array}{l}\text { An individual's emotional strategies to cope } \\
\text { with provocative ideas, events and experiences }\end{array}$ \\
\hline Reciprocal Determinism & $\begin{array}{l}\text { Dynamic interaction of individual, behavior, } \\
\text { and environment }\end{array}$ \\
\hline
\end{tabular}

from Redding, C.A., Rossi, J.S., Rossi, S.R., Velicer, W.F., \& Prochaska, J.O. (2000). Health Behaviour Model. The International Electronic Journal of Health Education, Vol. 3 (Special Issue), pp. 180-193. http://www.iejhe.siu.edu

Table 3. The Concepts of Social Cognitive Theory

Bandura conceptualized the effects on human behavior including the concept of human in terms of basic human capacities that are cognitive by their nature. Key concepts associated with the person include: personal characteristics, emotional arousal/coping, behavioral capacity, self-efficacy, expectation, expectancies, self-regulation, observational/experiential learning, and reinforcement. The Social Cognitive Theory also highlights the importance of cognitive and behavioral skills in building health behavior changes. For this reason, smokers who want to quit smoking but lack the necessary cognitive and behavioral skills to cope with stressful situations without smoking in the future are less likely to be successful in changing smoking behavior, no matter how enthusiastic they are (Redding et al., 2000). 


\subsubsection{Transtheoretical model}

In the last 20 years, research based on the Transtheoretical Model has revealed that there are some common principles of behavior changes that can be applied to several health behaviors. Examples of these behaviors are smoking cessation, exercise acquisition, sun protection, dietary fat reduction, condom use, supporting mammography screening, the spread of medicine use, coping with stress, and cessation of substance use. These problem behaviors are very important in regards to both clinical and public health, as they are closely related to an increase in the rate of illness and death and a decrease in the quality of life. The Transtheoretical Model is a model of intentional behavior change that provides a large volume of research and services in the field of problem behaviors. This model describes the relationships among: stages of change; processes of change; decisional balance, or the pros and cons of change; situational confidence, or self-efficacy in the behavior change; and situational temptations to relapse. (Prochaska et al., 2008). Table 4 explains the concepts that make up the Transtheoretical Model.

This model has some advantages over the other models. First of all, this model considers behavioral change as a process rather than an event. Then, by dividing the change process into phases and investigating which variables are associated with the improvement and the extent of their association, it presents important clues both in research and intervention development areas. The second advantage is that its emphasis on measuring concepts constituted a rigid base for the model. Among different problematic behaviors, different variables are associated with phase behaviors in each change phase. The Transtheoretical Model studies report significant similarities among different types of behavioral change. In the same way, it was found that phases of change had a predictable relationship with positive and negative aspects of behavioral changes, confidence in behavioral changes, the tendency to recur and processes of change (Redding 2000; Prochaska et al., 2008).

\subsection{Health education process}

The health education process consists of some elements such as data collection, diagnosis, planning and implementation.

\subsubsection{Data collection/diagnosis}

The data collection step is an important part of the education process. For example, in education that targets elderly individuals, it is essential to determine the real needs in detail at first in order to establish the needs and to meet those needs. Determination of the needs also helps us to see whether the educational program meets the real needs or not (Demirel, 2000). In needs analysis studies, the individual's and the related group's needs have to be determined. Determination of the needs that are peculiar to the individual or the group will enable us to determine the goals that are appropriate to the health education program to be prepared and will enable the individual to be more integrated with the society by showing self-managing behaviors. What does the society expect an elderly individual to accomplish basically? The program should be constructed with the regulations related to the answers to this question at first (Demirel, 2000; Gokkoca 2001). 


\begin{tabular}{|c|c|c|}
\hline & Concepts & Explanations \\
\hline \multirow{5}{*}{ 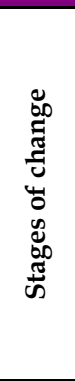 } & Pre-contemplation & $\begin{array}{l}\text { The absence of any intention to take action within the } \\
\text { following six months }\end{array}$ \\
\hline & Contemplation & $\begin{array}{l}\text { Intention to begin the healthy behavior within the next } \\
\text { six months }\end{array}$ \\
\hline & Preparation & $\begin{array}{l}\text { Being ready to act within the next } 30 \text { days and } \\
\text { passing some behavioral stages }\end{array}$ \\
\hline & Action & $\begin{array}{l}\text { Having a clearly-changed behavior for less than six } \\
\text { months }\end{array}$ \\
\hline & Maintenance & $\begin{array}{l}\text { Individuals at this stage changed their behavior } \\
\text { more than six months ago }\end{array}$ \\
\hline \multirow{2}{*}{ 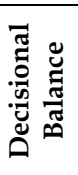 } & Pros & The benefits of change \\
\hline & Cons & The losses of change \\
\hline \multirow{2}{*}{ 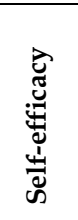 } & Confidence & $\begin{array}{l}\text { Trust in individuals' ability to perform } \\
\text { healthy behavior in spite of temptations }\end{array}$ \\
\hline & Temptation & $\begin{array}{l}\text { Encouragement to perform unhealthy behavior } \\
\text { in various tempting situations }\end{array}$ \\
\hline \multirow{11}{*}{ 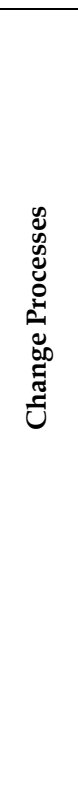 } & Consciousness Raising & $\begin{array}{l}\text { Gathering new facts, thoughts and tips that support } \\
\text { healthy behavior change }\end{array}$ \\
\hline & Dramatical Relief & $\begin{array}{l}\text { Having negative emotions (fear, worry, anxiety) that are } \\
\text { part of the unhealthy behavioral risks }\end{array}$ \\
\hline & Selfreevaluation & $\begin{array}{l}\text { Being aware of the fact that behavior change is an } \\
\text { important part of an individual's personality }\end{array}$ \\
\hline & Environmental & Becoming aware of the negative effect of the \\
\hline & Reevaluation & $\begin{array}{l}\text { unhealthy behavior and the positive impact of healthy } \\
\text { behavior on their proximal social and / or physical } \\
\text { environment }\end{array}$ \\
\hline & Self-liberation & Full commitment to change \\
\hline & Helping Relationships & $\begin{array}{l}\text { Searching and using social support for healthy } \\
\text { behavior change }\end{array}$ \\
\hline & Counterconditioning & $\begin{array}{l}\text { Replacement of unhealthy behaviors or cognition with } \\
\text { more healthy alternatives }\end{array}$ \\
\hline & Reinforcement Management & $\begin{array}{l}\text { Rewarding positive behavior change more and /or } \\
\text { reducing the award to unhealthy behaviors }\end{array}$ \\
\hline & Stimulus Control & $\begin{array}{l}\text { Eliminating clues or reminders to unhealthy behavior or } \\
\text { using clues or reminders to promote healthy behavior }\end{array}$ \\
\hline & Social Liberation & $\begin{array}{l}\text { Becoming aware of the fact that social norms have } \\
\text { changed in the direction of supporting healthy behavior } \\
\text { change. }\end{array}$ \\
\hline
\end{tabular}

From Redding, C.A., Rossi, J.S., Rossi, S.R., Velicer. W.F., \& Prochaska, J.O. (2000). Health Behaviour Model. The International Electronic Journal of Health Education, Vol. 3 (Special Issue), pp. 180-193.

http://www.iejhe.siu.edu

Table 4. The Concepts of the Transtheoretical Model 
While determining the educational needs, and in the data collection step, the knowledge, attitudes and behaviors that will be acquired by the target group are taken into consideration. In order to learn this, it is necessary to live together with the target group, establish meetings, to know them, to get information from their social leaders, to benefit from the data of the related literature, and to examine their health records (Hacralioglu, 2009). While determining educational needs, the following questions have to be answered:

1. What is the general situation?: There should be sufficient information about the characteristics, number and the level of success of the educational programs for the elderly; the economic resources of these educational programs, the proficiency level of educators, and educational materials and the technologies.

2. What is known about the participants?: The participants' cognitive, affective, and physical abilities, their previous experiences, their perceptions of themselves and the society can be evaluated (Demirel, 2000). In order to achieve this, an examination HBDH (REALMRapid Estimate of Adult Literacy) can be implemented to determine the cognitive level of the individual and his or her knowledge level in the treatment process in a short time like one or two minutes. In addition, individuals can be asked how they feel while filling out the documents (Rojda \& George, 2009).

3. What is the content of the educational materials like?: The material to be prepared should be checked for their suitability and consistency with the aims of the education and for legibility for the elderly (Demirel, 2000). In order to evaluate the material, a checklist can be prepared and implemented to see whether the material is consistent and suitable and can easily be read. In addition, with some tools like Fleisch-Kincaid Grade Level and SMOG (Simple Measure of Gobbledygook), the number of the sentences and the words can be counted and the suitable material can be decided on (Rojda \& George, 2009).

\subsubsection{Planning}

While planning the health education plan, elderly individuals' socio-economic level and cultural background should be taken into consideration. Therefore, the material to be used in the education should be chosen carefully. The level of instruction should be parallel to the understanding level of the individuals. In addition, the place and the duration of the implementation must be indicated in the plan (Hacialioglu, 2009).

Who will train?/ The trainer
Who will get the education? /
The target group
What to teach? / The subject
Why to teach? / The aim


How to teach/ The methodology discussing, and etc.

Where to implement / The place
The time of the education/The date
The duration of the education

A health education plan must be designed based on some principles. These principles are:

- Functionality: The plan must have the qualities and the content to achieve the educational goal or goals. And it must consist of the goals that can be measured, beneficial, action-based, and valid for real life.

- Flexibility: The plan must be creative and flexible, be able to answer the individuals' changing needs and be open to new developments.

- Realistic: The health education plan must not include over-idealistic and utopic aims.

- Practicability: Not only the people who prepared the plan but also other people can use the health education plan easily at different times.

- Being Scientific: The health education plan should include scientific qualities in terms of the knowledge and the behavior to be gained.

- Suitability to the social values: The plan shouldn't contradict the life philosophy, ideals, beliefs and the values of the society where it is implemented.

- Being Economical: The costs of the implementation steps of the health education plan and the behaviors to be acquired should be affordable (Tabak, 2000).

Another factor to be considered in the planning is the determination of learner-centered objectives. The objectives are defined as the changes in the behaviors of the individual or the group. The objectives have priority in the determination of the target group and the content of the educational program. Besides, the objectives should be determined first in order to decide on the methodology and the techniques to be used in the program. The goals can be determined as the short and long-term (Demirel, 2000; Tabak, 2000). For example, teaching an elderly individual with type II diabetics how to inject insulin is a short-term objective. On the other hand, it is a long-term objective for the same individual to manage the illness effectively.

The objectives to be determined in health education can be developed for individuals' cognitive, affective and psychomotor skills. The cognitive field is related to the knowledge and the mental abilities that are derived from knowledge (Demirel, 2000; Tabak, 2000). The cognitive domain objectives related to an elderly individual's health education can be written as follows:

While preparing an educational program, the trainer, the target group, the aim of the education, the methodology to be used in the education, and the place and time of the education should be clearly determined (Demirel, 2000; Hacialioglu, 2009). For example, a health education plan for the elderly individuals who cannot feed themselves properly can be as follows. 


\begin{tabular}{l|l}
$\begin{array}{l}\text { Knows the complications of Type II } \\
\text { diabetics. }\end{array}$ & $\begin{array}{l}\text { Tells the normal blood pressure values. } \\
\text { Interprets the relation between } \\
\text { Knows the normal blood glucose level. } \\
\text { Plans his/her dietary program. }\end{array}$ \\
$\begin{array}{l}\text { Evaluates his/her diet's effects on the type } \\
\text { Tells the associations related to the } \\
\text { hypertension. } \\
\text { II diabetics. }\end{array}$ & $\begin{array}{l}\text { Evaluates the effects of regular health } \\
\text { controls for the effective management of } \\
\text { hypertension. } \\
\text { Knows the complications of Type II } \\
\text { diabetics }\end{array}$ \\
Knows the normal blood glucose level. & $\begin{array}{l}\text { Interprets the relation between } \\
\text { hypertension and salt. }\end{array}$ \\
\hline
\end{tabular}

The affective domain target behaviors are related to the emotion and value systems. Interest, attitude, appreciation, belief, etc. include behaviors that are difficult to measure (Demirel, 2000; Tabak, 2000). Affective domain objectives can be written as follows:

Believes in the importance of measuring the blood glucose at regular intervals.

Is willing to participate in the scientific and social activities related to diabetics.

Accepts the new diet special to him or her.

Cares about the continuation of the regular physical exercises.

Believes in the importance of measuring the blood glucose at regular intervals.

Is willing to participate in the scientific and social activities related to diabetics.
Is careful about keeping the blood pressure at correct levels.

Is willing to follow the up-to-date resources about hypertension.

Accepts being an active member of the associations related to hypertension.

Believes in the importance of regular health controls for the effective management of hypertension.

Is careful about keeping the blood pressure at correct levels.

Is willing to follow the up-to-date resources about hypertension.

Finally, the psychomotor domain includes skills that require the individual's muscle and mind coordination (Demirel, 2000, Tabak, 2000). Psychomotor domain objectives can be written as follows:

Follows the stages of the measurement in the blood glucose meter.

Measures the blood sugar level alone.

Performs a proper physical preparation for the measurement of blood sugar.

Applies a self-insulin injection.
Follows the stages of blood pressure measurement.

Measures blood pressure properly.

Takes a proper position when blood pressure rises.

Prepares hypertension drugs properly. 
Some programming approaches should be utilized so that the content can be managed consistent with the objectives. These can be summarized as linear, spiral and modular programming approaches. The linear programming approach is used to arrange the topics, which consist mainly of learning that is successive, closely related or a prerequisite for each other. Spiral approach programming involves addressing issues over and over when necessary. Finally, in the modular programming approach, the subjects to be learnt are divided into modules, modules are connected to each other and each module gains meaning within itself. The content should be offered after determining the most appropriate programming approach for the elderly. What programming approach to choose should be decided by considering factors such as learning preferences, cognitive-affective and psychomotor skill levels of the target elderly population, qualifications of the educator and available sources (Demirel, 2000). After organizing the content based on the appropriate programming approach, the next step is to decide with which method, technique, material, etc. to present that content. The group's characteristics, size, target learning domains, duration of education, funds, available educational resources, the educator's qualities and so on have to be taken into account when choosing educational methods tailored for the elderly (Demirel, 2000; Tabak 2000).

Methods such as lectures, discussions, questions and answers, demonstrations, role-plays, etc. can be used according to the goals and objectives in the process of education. However, no matter what method is used, there should be active participation of the elderly, feedback and a supportive communication style (Tabak, 2000). Therefore, educational environments should be designed in a way that allows everyone to see each other easily, have eye contact with each other comfortably, and should be free of hierarchy. Common seating arrangements are U-type, team style, circle, and work units seating orders; arrangements can be shaped according to the educational method chosen.

In order to determine the location and time for health education, educators and the target group should take the decision jointly. It would be appropriate to choose convenient times and places (Tabak, 2000). In addition, the place of education must have efficient acoustic features; enough space for writing activities and tools like wheelchairs, sticks and walkers; a suitable temperature; non-slip stairs and a floor, and comfortable chairs with back support on which individuals of different physical sizes can comfortably sit (Grandal, 2008).

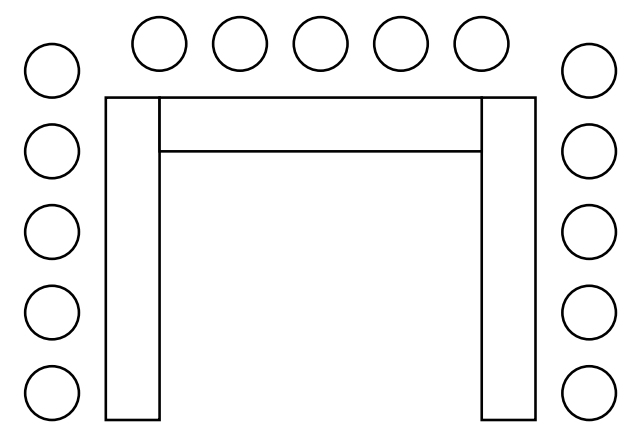

Fig. 1. U Seating Order 


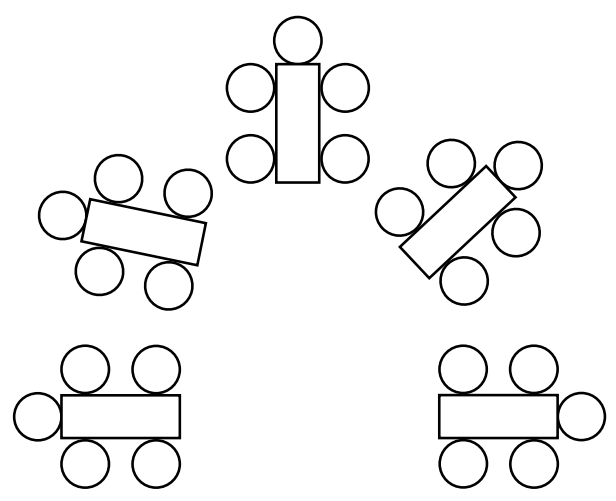

Fig. 2. Team Seating Order

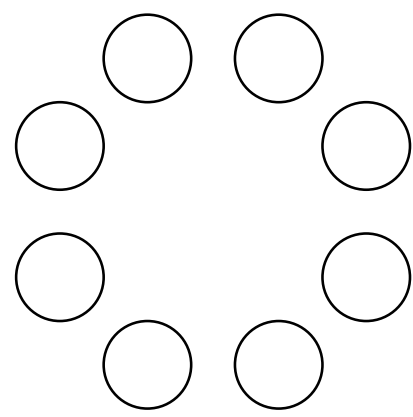

Fig. 3. Circle Seating Order

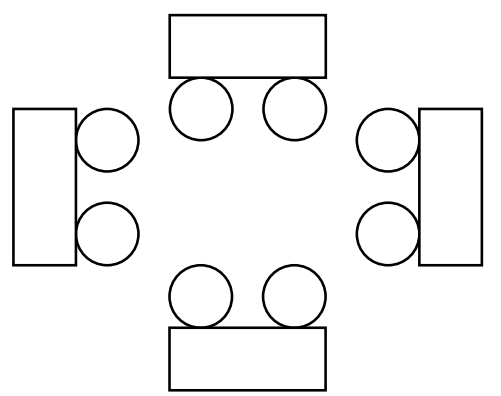

From Demirel, Ö (2000). Learning Art. Ankara, Turkey: Pegem A Publishing.

Fig. 4. Working Units

Another component of this educational process is materials; the answer to the following question is important when choosing educational materials: Are the font of these materials large enough for the elderly to read easily? The font of educational materials should be large enough and the background should contain white areas because it is easier to read when the background largely consists of white areas. Also, images and graphics should be preferred as they make the message clearer. Words and posters should be used instead of long 
paragraphs (Rojda \& George, 2009). In addition, medical/health terminology (i.e., medical jargon) should be avoided in the educational materials designed specifically for the elderly (Figure $5 \mathrm{a}, \mathrm{b}$ ). Finally, another focus point in the health promotion for the elderly is encouraging health promotion experts to acquire the necessary skills so that they can develop culturally and linguistically appropriate health education materials (Wallace, 2004).

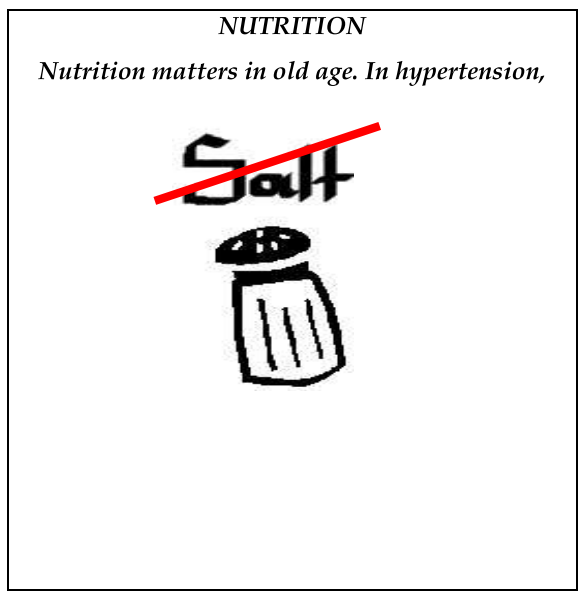

a.

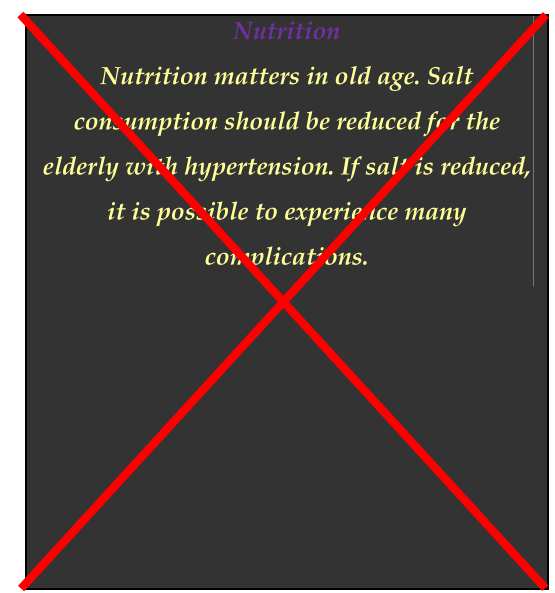

b.

Fig. 5. a. Appropriate educational material. b. Inappropriate educational material

\subsubsection{Implementation}

It is the phase that involves organizing the learning experiences that enable the individuals to gain the targeted behaviors. Learning experiences are to be oriented to the individual, and must be arranged in a specific order. This arrangement can be ordered as introduction or preparation activities, development activities, and final activities (Demirel, 2000). The individual must be informed in advance about which qualities and competences he or she will have by the end of the educational process. Afterwards, the necessary content to achieve these goals should be indicated. The activities planned to be implemented must be assessed during improvement activities (Demirel, 2000).

It is crucial to pay specific attention to the language used and communication when you apply the health education process. The essential strategies to communicate effectively with elderly individuals can be summarized as follows:

\section{Improving communication with an elderly individual}

1. Using the principles of individual-centered care

- Knowing the person to be educated: An educator that works with elderly individuals is required to be able to use his or her tone of voice, facial expressions, gestures, and the words correctly, and have the ability to listen without expressing criticism, sadness, or complaint. 
- Applying the principles of gentle listening: The educator must listen what is being said without interrupting the person, or "tuning out" his or her words. The educator should understand what the real problem is.

- Allowing time to "right" (positive aspects of their lives) things as well as talking about problems: The individual's positive qualities/strengths must be stressed while talking about problems. Emphasizing "wrong" things can create a bad feeling. Listen to personal stories and experiences properly. What does the person say? What is the individual doing to improve his or her power and abilities?

- Slow down and focus on the individual: What is he saying? What is he conveying? The educators shouldn't have a hasty or duty-based approach. Attention should be paid not only to what they say about their health but also to other things they mention. Think about being an old person, he or she has lived a long life. What is the meaning of the current situation for him or her?

2. Arrange the environment and the routines

- Adjust changes in seeing: An older adult can see you better in bright light. Avoid standing too close in order not to being seen blurred. You should stand in front of the person to be seen easily. Yellow and red or green and blue colors should be used for signs and markers.

- Adjust to changes in hearing: Make sure that the individual can read your lips. If it is necessary to speak out, a low tone of voice should be used. Ear wax accumulation ought to be checked as it can prevent hearing. Hearing aids and batteries should be checked.

- Pay attention to environmental effects: in educational environments, the noise must be prevented. Rooms must be lit enough to see them and let them read your lips. Elderly individuals mustn't worry about others' hearing what they say (privacy respected).

- Evaluate the personal comfort level of the individual: They should be physically comforted.

Hunger, thirst, pain, or the need for the toilet must be eliminated. What they think and feel should be evaluated for their effects on learning.

3. Adjust your interaction with the elderly

- Think about the approach and the language: They should be given time to respond to your questions, or ask questions (Note: The reaction time slows down). Familiar and understandable words should be used, and medical terminology or slang should be avoided. The educator should be clear and understandable, and should not use long explanations or instructions.

- $\quad$ Adapt to changes in responses: If you need to improve participation, yes/no questions should be used. Important points should be written in large fonts. Use physical gestures to enhance verbal communication. Questions with only two options may be used in order to promote success.

- Help them think by giving clues like "When?" or "How long ago?" Apologize for misunderstandings and provide an explanation.

4. Adapt your approach to accommodate changes in EXPRESSION: Listen for meaningful words and ideas, trying to identify the main theme or goal. Respond to the person's emotional tone and validate feelings (e.g., understandable to feel frustrated, angry). Accept/understand cursing or other foul language as an expression of distress and discomfort - not an "insult" to you. Using guessing (e.g., trying to replace words the 
person is having difficulty saying) based on how well you know the person and the relationship you have; guessing can been annoying to the person and may further increase confusion (Smith, 2006; Cornett, 2011).

\subsubsection{Evaluation}

The success of health promotion can be evaluated by measuring to what extent the intended objectives can be achieved. What were the individual's knowledge, attitudes and skills on the subject before the education? What have they accomplished after the training? How much lack of information has been fixed? Has an attitude change been provided? Have the skills been gained? How much have they gained? What more skills should be gained? The correct answers to these questions, etc. are obtained by measurement and evaluation (Hacralioglu 2009).

Evaluation processes are usually performed with qualitative and quantitative assessment techniques. The knowledge level of elderly individual/individuals participating in a health education program can be estab;ished only through post-training tests. During the evaluation process, qualitative methods such as observation and interviews can also be used. Qualitative evaluation includes the views and expectations of educational program participants and other people related to the program and provides a much broader perspective than quantitative assessment (Tabak, 2000). In recent years, however, these two types of assessment have been used together in a holistic approach to minimize the disadvantages of both methods.

\section{References}

Bastable, S.B (2008). Nurse as an Educator, Jones \& Bartlett Learning, pp. 1-667.

Bikmaz, F.H. (2006). Self-efficacy Beliefs, In: Individual Differences in Education. Y. Kuzgun, D. Deryakulu (Eds), Ankara, Turkey.

Champion, V.L. \& Skinner, C.S. (2008). Health Belief Model, In: Health Behavior and Health Education, K. Glanz, B.K. Rimer, K., Viswanat (Eds.), 45-62, Jossey-Bass, ISBN 978-07879-9614-7, San Francisco, USA.

Choi, W.H.H., Hui, G.K.H., Lee, A.C.K. \& Chui, M.M. L. (2010). Student Nurses' Experiences and Challenges in Providing Health Education in Hong Kong. Nurse Education Today, Vol.30, pp. 355-359.

Connell, C.M. (1999). Older Adults in Health Education Research: Some Recommendations. Health Education Research Theory \& Practice, Vol. 14, No.3, pp. 427-431.

Cornett S. (August 2011). Teaching the Elderly. 20.08.2011. Available from http://medicalcenter.osu.edu/patiented/materials/pdfdocs/employee/elderly.pdf

Demirel, O. (2000). Learning Art. Ankara, Turkey: Pegem A Publishing.

DeYoung, S. (2009). Learning Theory. In: Teaching Strategies for Nurse Educators, 23-30. New Jersey, USA: Pearson Education.

Doucette, W.R., Andersen, T.N.(2005). Practitioner activities in patient education and drug therapy monitoring for community dwelling elderly patients. Patient Education and Counselling.Vol.57, pp.204-2010.

Glanz, K., Rimer, B.K. \& Viswanat, K. (2008). Theory, Research, and Practice in Health Behavior and Health Education. In: Health Behavior and Health Education, K. Glanz, 
B.K. Rimer, K. Viswanat (Eds.) 23-38, Jossey-Bass, ISBN 978-0-7879-9614-7, San Francisco, USA.

Gokkoca, F.Z.U. (2001). Adult Education in Relation to Health Education. STED, Vol. 10, No.11, pp. 412-414.

Grandal, K. (August 2011). Class Acts: A+ Educational Activities for the Elderly in Healthcare Facilities. 02.08.2011. Available from www.recreativeresources.com

Hacialioglu N. (2009). Health Education. In: Public Health Nursing, B. Erci (Ed.), 166-181. Turkey: Göktug Publishing.

Hoving, C., Visser, A., Mullen, P.D. \& Borne, B. (2010). A History of Patient Education by Health Professionals in Europe and North America: From Authority to Shared Decision Making Education. Patient Education and Counseling, Vol. 78, pp. 275-281.

Kahn, M.H., Goto, R., Sonoda T., Sakauchi F., Washio M., Kobayashi K., Mori M. (2004). Impact of health education and screening over all-cause mortality in Japan: evidence from a cohort study during 1984-2002. Preventive Medicine. Vol.38, pp.786792.

Karaoz, S. \& Aksayan, S. (2009). Ageing and Nursing. In: It's called September - Ageing in Health Sciences. MN. Gacar (Ed.), 463-537. Istanbul, Turkey: Nobel Medical Publishing.

Koh, L.C. (2011). Student attitudes and educational support in caring for older people - A review of literature. Nurse Education in Practice.pp.1-5.

Kurt, İ. (2000). Adult Education. Istanbul, Turkey: Nobel Medical Publishing.

Leung, A., Chi, I. \& Lui, Y.H. (2006). A Cross-Cultural Study in Older Adults' Learning Experience. Asian J Gerontol Geriatr, Vol. 1, pp. 78-83.

Liu, E., Wong, E. (1997). Health Care For Elderly People. Research and Library Services Division Provisional Legislative Council Secretariat's Document, Hong Kong.

Montaño, D.E. \& Kasprzyk, D. (2008). The theory of reasoned action, theory of planned behavior, and Integrated Behavioral Model. In: Health Behavior and Health Education. K. Glanz, B.K. Rimer, K. Viswanat (Eds.), 67-92, Jossey-Bass, ISBN 978-0-7879-96147, San Francisco, USA.

Prochaska, J.O., Redding, C.O. \& Evers, K.E. (2008). The Transtheoretical Model and Stages of Change. In: Health Behavior and Health Education, K. Glanz, B.K. Rimer, K. Viswanat (Eds.), 97-117, Jossey-Bass, ISBN 978-0-7879-9614-7, San Francisco, USA.

Rana, A.K.M.M., Kabir, Z.N., Lundborg, C.S. \& Wahlin, A. (2010). Health Education Improves Both Arthritis-related Illness and Self-rated Health: An Intervention Study Among Older People in Rural Bangladesh. Public Health, Vol.124, pp. 705712.

Redding, C.A., Rossi, J.S., Rossi, S.R., Velicer, W.F. \& Prochaska, J.O. (2000). Health Behaviour Model, The International Electronic Journal of Health Education, Vol.3 (Special Issue), pp. 180-193. Available from http://www.iejhe.siu.edu

Reicherter, E.A. \& Revenda-Greene, R. (2005). Wellness and Health Promotion Educational Applications for Older Adults in the Community. Topics in Geriatric Rehabilitation, Vol. 21, No. 4, pp. 295-303.

Rojda, C. \& George, N. M. (2009). The Effect of Education and Literacy Levels on Health Outcomes of the Elderly. The Journal for Nurse Practitioners (JNP), pp. 115-119. 
Shen, Q., Karr, M. , Ko, A., Chan, D.K.Y., Khan, R. \& Duvall D. (2006). Evaluation of a Medication Education Program for Elderly Hospital In-Patients. Geriatric Nursing, Vol.27, No.3, pp.184-192.

Smith, M. (2006). Getting the Facts: Communicating with the Elderly. The Geriatric Mental Health Training Series, for the Hartford Center of Geriatric Nursing Excellence, College of Nursing, University of Iowa. Available from

http://www.nursing.uiowa.edu/hartford/nurse/effective_communication/Com mun-Support-Mat.pdf

Tabloski, P.A. (2010). Challenges of Aging and Cornerstones of Excellence in Nursing Care. In: Gerontological Nursing, 87-343, Pearson Education, ISBN 978-0-13-503810-9, New Jersey, USA.

Tabak, R.S. (2000). Health Education. Ankara, Turkey: Somgür Publishing.

Wallace L. S. (2004). The Impact of Limited Literacy on Health Promotion in the Elderly. Californian Journal of Health Promotion, Vol.2, No.3, pp. 1-4.

Vintila, M., Marklinder, I., Nydahl, M., Istratı, D. \& Kuglisı, A. (August 2011). Health behavior of the elderly: Between needs and reality: A comparative study, 02.08.2011, Available from www.communityhealth.eu/.../Article\%20Revista\%20de\%20psihologie\%20aplicata.pdf 


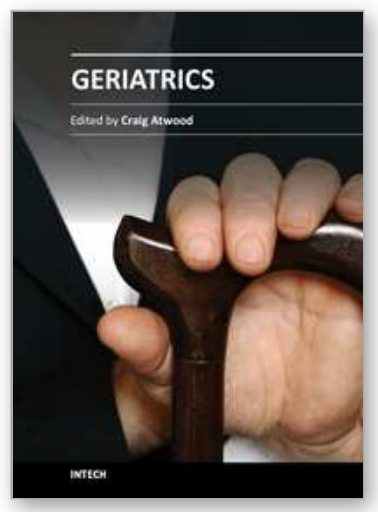

\author{
Geriatrics \\ Edited by Prof. Craig Atwood
}

ISBN 978-953-51-0080-5

Hard cover, 246 pages

Publisher InTech

Published online 24, February, 2012

Published in print edition February, 2012

With the baby boomer generation reaching 65 years of age, attention in the medical field is turning to how best to meet the needs of this rapidly approaching, large population of geriatric individuals. Geriatric healthcare by nature is multi-dimensional, involving medical, educational, social, cultural, religious and economic factors. The chapters in this book illustrate the complex interplay of these factors in the development, management and treatment of geriatric patients, and begin by examining sarcopenia, cognitive decline and dysphagia as important factors involved in frailty syndrome. This is followed by strategies to increase healthspan and lifespan, such as exercise, nutrition and immunization, as well as how physical, psychological and sociocultural changes impact learning in the elderly. The final chapters of the book examine end of life issues for geriatric patients, including effective advocacy by patients and families for responsive care, attitudes toward autonomy and legal instruments, and the cost effectiveness of new health care technologies and services.

\title{
How to reference
}

In order to correctly reference this scholarly work, feel free to copy and paste the following:

Ayla Kececi and Serap Bulduk (2012). Health Education for the Elderly, Geriatrics, Prof. Craig Atwood (Ed.), ISBN: 978-953-51-0080-5, InTech, Available from: http://www.intechopen.com/books/geriatrics/healtheducation-for-elderly-people

\section{INTECH}

open science | open minds

\author{
InTech Europe \\ University Campus STeP Ri \\ Slavka Krautzeka 83/A \\ 51000 Rijeka, Croatia \\ Phone: +385 (51) 770447 \\ Fax: +385 (51) 686166 \\ www.intechopen.com
}

\author{
InTech China \\ Unit 405, Office Block, Hotel Equatorial Shanghai \\ No.65, Yan An Road (West), Shanghai, 200040, China \\ 中国上海市延安西路65号上海国际贵都大饭店办公楼 405 单元 \\ Phone: +86-21-62489820 \\ Fax: +86-21-62489821
}


(C) 2012 The Author(s). Licensee IntechOpen. This is an open access article distributed under the terms of the Creative Commons Attribution 3.0 License, which permits unrestricted use, distribution, and reproduction in any medium, provided the original work is properly cited. 